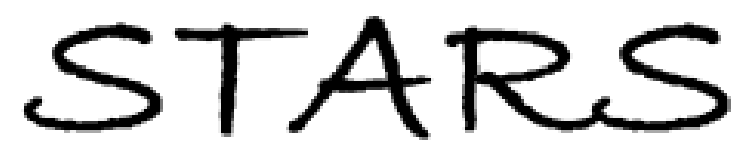

University of Central Florida

STARS

$1-1-2012$

\title{
Online Sexual Activity: Cross-National Comparison Between United States and Peruvian College Students
}

\author{
Rodrigo Velezmoro \\ University of Central Florida \\ Charles Negy \\ University of Central Florida \\ Jose Livia
}

Find similar works at: https://stars.library.ucf.edu/facultybib2010 University of Central Florida Libraries http://library.ucf.edu

This Article is brought to you for free and open access by the Faculty Bibliography at STARS. It has been accepted for inclusion in Faculty Bibliography 2010 s by an authorized administrator of STARS. For more information, please contactSTARS@ucf.edu.

\section{Recommended Citation}

Velezmoro, Rodrigo; Negy, Charles; and Livia, Jose, "Online Sexual Activity: Cross-National Comparison Between United States and Peruvian College Students" (2012). Faculty Bibliography 2010s. 3441.

https://stars.library.ucf.edu/facultybib2010/3441

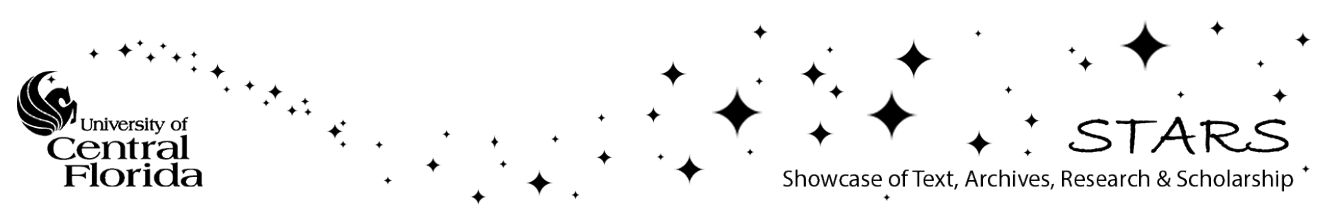




\title{
Online Sexual Activity: Cross-National Comparison Between United States and Peruvian College Students
}

\author{
Rodrigo Velezmoro $\cdot$ Charles Negy $\cdot$ Jose Livia
}

Received: 5 July 2010 / Revised: 3 February 2011 / Accepted: 25 July 2011 / Published online: 15 November 2011

(C) Springer Science+Business Media, LLC 2011

\begin{abstract}
The current generation of college students commonly uses the Internet for myriad sexually-related purposes. Yet, it has been suggested that usage of the Internet for sexual purposes might lead to psychological problems. In this study, undergraduate students from a public university in the U.S. $(n=$ $320)$ and Peru $(n=251)$ completed questionnaires addressing their online sexual activity (OSA), psychological adjustment, and family environment and communication. Results indicated that Peruvians used the Internet significantly more than U.S. students to view sexually-explicit material (SEM), find sexual partners, and search for sex-related information. Men, irrespective of nationality, used the Internet to view SEM significantly more than women. Social support, religiosity, and erotophilia were found to moderate the relations between nationality and OSA. In absolute terms, both national groups, on average, engaged in OSA a relatively low number of hours each week. Further, no differences were found in maladjustment between those who engage in OSA and those who do not, suggesting that concerns over OSA are probably unwarranted.
\end{abstract}

Keywords Internet use - College students · Sexual activity · Online sexual-activities $\cdot$ Internet abuse

\section{Introduction}

In the last two decades, much attention has been directed toward the Internet for being a new vehicle for human sexuality (Carroll

R. Velezmoro · C. Negy $(\bowtie)$

Department of Psychology, University of Central Florida, 4000 Central Florida Blvd., Orlando, FL 32816-1390, USA e-mail: Charles.Negy@ucf.edu

J. Livia

Department of Psychology, Universidad Nacional Frederico Villarreal, Lima, Peru et al., 2008). Although erotic material has been widespread since the invention of the Gutenberg press, the Internet has facilitated such access (Bakker \& Taalas, 2007; Cooper, Putnam, Planchon, $\&$ Boies, 1999). Online sexual activity (OSA) refers to any sexual activity online, whether for entertainment, seeking partners, searching for information or commerce (Cooper, Griffin-Shelley, Delmonico, \& Mathy, 2001). This includes shopping for and purchasing sexual material and, to a much lesser degree, sexual predation (Cooper, Morahan-Martin, Mathy, \& Maheu, 2002). Although sexual crimes do occur online, the vast majority of individuals who engage in OSA do not appear to be pathological and do not seem to manifest negative consequences from OSA (Cooper, Galbreath, \& Becker, 2004).

Apart from deviant and illegal behavior, however, some individuals do appear to suffer negative consequences from their OSA (Cooper et al., 2001). Online sexual problems arise when people suffer relationship, financial or any type of problem related to their usage of the Internet for sex-related purposes. From a broader perspective, some argue that healthy sexuality equates with intimacy with a partner without thinking about something or someone else, and that engaging in OSA may lead to sexual dissatisfaction (Schwartz, Galpernin, \& Masters, 1995). However, given the variation in sexual attitudes across cultures (e.g., Ahmad \& Bhugra, 2010; Hofstede, 1998), what constitutes healthy sexuality is open to discussion. Moreover, equating healthy sexuality with intimacy tends to simplify human sexuality given that sexual behavior among humans has never been limited to intimacy or even to reproductive purposes (Meston \& Buss, 2007) and has always found a way to manifest itself in new technology.

The current generation of college students, both in the U.S. and in many other parts of the world, has grown up during the age of the Internet and may be susceptible to suffering consequences due to their Internet usage (Cooper et al., 2001). Given that sexual exploration and the pursuit of intimate relationships typically cooccur during late adolescence and young adulthood (Erikson, 
1959), it is reasonable to expect that college students would make use of the Internet towards these endeavors (Boies, Cooper, \& Osborne, 2004). Further, in some ways, being a college student in the U.S. may facilitate OSA given the pervasive promotion of Internet usage by faculty and administration for multiple college-related purposes (Young, 2004) and a newfound autonomy from parental oversight (Kandell, 1998).

Some researchers have suggested that college students may have more Internet-related problems than other populations (Chou, Condrun, \& Belland, 2005; Morahan-Martin \& Schumacher, 2000). Examining college students exclusively, Boies et al. (2004) found that, on average, college students who engaged in OSA reported being less satisfied with their sexual offline life than those who did not engage in OSA. Boies et al. concluded that those who used the Internet for meeting social needs may be at risk for jeopardizing social bonds. We note, however, that it could be that not having well developed social relationships causes individuals to turn to the Internet to fill that void. In addition, some have argued that college students are more likely to become "addicted" to the Internet due to increased accessibility and newfound freedom (Young, 1999). The validity of this construct (i.e., Internet addiction) is open to debate (Eppright, Allwood, Stern, \& Theiss, 1999; Shaffer, Hall, \& Vander Bilt, 2000) and no standard definition exists for being addicted to the Internet (Chou et al., 2005). Further, Klein (2006) argued that Internet addiction simply represents another attempt by U.S. society to pathologize sex and sexuality. Other attempts to pathologize sex include abstinence-only programs which have recently been the only form of sex education funded federally in the U.S, as well as state laws restricting certain sexual acts between consenting adults, even if they are rarely enforced.

College students engage in many forms of OSA (Boies, 2002). Viewing sexually explicit material (SEM) is common and controversial. Erotic Internet sites offering pictures, videos, and live-chatting, as well as online sex shops, are ubiquitous both nationally and internationally (Barak \& Fisher, 2002). Goodson, McCormick, and Evans (2000a) found that $43 \%$ of U.S. college students had viewed SEM at least once, with $3 \%$ viewing SEM often. Boies (2002) found that $40 \%$ of Canadian college students used the Internet to find SEM. More recently, Carroll et al. (2008) found that, among U.S. college students, $87 \%$ of men and $31 \%$ of women acknowledged viewing SEM via the Internet.

Research findings on the effects of exposure to SEM, irrespective of format, are complex and controversial (Barak, Fisher, Belfry, \& Lashambe, 1999; Hald \& Malamuth, 2008; OddonePaolucci, Genuis, \& Violato, 2000). Some researchers hold the view that SEM may reduce the shame often associated with sexuality and sexual urges and that, as with all OSA, SEM can improve one's offline sex life (Cooper et al., 2004). By contrast, others have argued that SEM desensitizes people and negatively influences their behavior and attitudes (Zillmann \& Weaver, 1999). It is likely, however, that exposure to SEM — both online and offline - simply increases openness to sexuality and sex. For example, Zillmann and Bryant (1988) found that experimental exposure to SEM led to more open views of sexuality. Other researchers, however, have suggested that pre-existing values likely influence whether people access the material (Carroll et al., 2008).

Using the Internet to find partners and seek sex-related information also are popular forms of OSA (Griffiths, 2004). Boies (2002) studied 760 university students' OSA and found that roughly $42 \%$ had reported using the Internet to find a romantic partner. McFarlane, Bull, and Rietmeijer (2002) also found that some college students used the Internet to find sexual partners and that those who did were more likely to divulge personal information online and less likely to have been tested for sexually transmitted infections (STIs), compared to college students who did not use the Internet to find partners. In addition, college students appear to obtain more information about sex, contraceptives, and even information related to sexual identity from the Internet than from parents or peers (Escoffery et al., 2005; Sprecher, Harris, \& Meyes, 2008). For example, among a sample of 506 college students, Goodson, McCormick, and Evans (2001) found that $56 \%$ of men and $35 \%$ of women reported using the Internet to obtain information related to sex and sexuality. Canadian college students also have been found to use the Internet for these purposes, though to a lesser degree. Boies (2002) found that $21 \%$ of Canadian students reported using the Internet to obtain such information.

\section{OSA Cross-Culturally: The Case of Peru}

Although U.S. citizens may produce and consume the majority of SEM, this material is consumed throughout the world (Mackay, 2001). SEM, however, may not be consumed in the same manner. Countries vary in their acceptance of different forms of sexual activity and cultures influence how individuals perceive and experience sexuality (Suggs \& Miracle, 1993). Studying sexual expression in different countries sheds light on similarities and differences across cultures (Balderston \& Guy, 1997). Moreover, most studies have either examined U.S. (Goodson et al., 2001), Canadian (Boies, 2002), European (Cooper, Månsson, Daneback, Tikkanen, \& Ross, 2003) or Taiwanese populations (Lo \& Wei, 2005).

The U.S. and Peru have distinct cultures and histories, yet, the two countries share similar, but unique ironies in the ways civil liberties and the acceptance of sexuality are manifested. The U.S. is a country that embraces civil liberties related to its democratic foundations, but, nonetheless, holds relatively conservative views toward sex and sexuality perhaps because of its Judeo-Christian heritage (Klein, 2006). Similar to U.S. citizens, Peruvian citizens tend to hold socially conservative values — values that, in the case of Peru, have been influenced by traditional Catholic ideology (Caceres, Cueto, \& Palomino, 2008). Unlike the U.S., however, contemporary Peruvian culture has developed from a mixture of Spanish and indigenous cultures. Indigenous cultures throughout the Americas historically have fewer prohibitions against 
sex and sexuality relative to Western, Christian-based cultures (Tannahill, 1992). As a result, Peruvians may, on average, be somewhat more open to individual sexual activity that occurs privately.

\section{The Current Study}

This was an exploratory study designed to compare Internet usage for sexually-related purposes between U.S. and Peruvian college students. At a more specific level, we hoped to clarify the role of other relevant variables that might shed light on the two cultural groups' potentially discrepant levels of OSA. We hypothesized that U.S. college students would engage in OSA significantly more than Peruvian college students. This hypothesis was based on a presumed increased accessibility to the Internet and the promotion of individual liberties found in the U.S. We also hypothesized that men-irrespective of nationality-would report significantly more OSA than women. As previous studies have shown, men engage in OSA and consume more SEM than women (Carroll et al., 2008; Goodson et al., 2001). Finally, it was hypothesized that OSA would minimally, if at all, be linked with maladjustment. More specifically, if OSA is found to be associated with indices of maladjustment and problematic behaviors as other studies have suggested, we expected that usage of the Internet for general, non-sexually related purposes also would be associated with poor psychological adjustment and problematic behaviors. Additional variables were assessed in order to glean insight about potential correlates of OSA, as well as to possibly elucidate their role, if any, in accounting for cross-national differences in Internet usage. They included a set of family and support-related variables, as well as the constructs of religiosity and erotophiliaerotophobia. Inclusion of these latter two sets of variables was intended to elucidate their potential moderating role in accounting for potential group differences between the U.S. and Peru in OSA as well as for potential associations between OSA and psychological adjustment.

\section{Method}

Participants

Participants included 320 undergraduate students (195 females, 125 males) attending a university in the southeastern region of the U.S. and 251 undergraduate students (94 females, 157 males) attending a university in Lima, Peru. The two universities were somewhat comparable in that they both were public institutions located in urban settings. The mean ages of the U.S. and Peruvian samples was 18.6 and 21.3 years $(S D \mathrm{~s}=.52$ and 2.79), respectively. Peruvian students were sampled from a broader range of classes, including advanced courses, which likely explain the age differences. Regarding ethnicity, participants in the U.S. sample selfidentified as the following: 206 non-Hispanic Whites, 39 Hispanics/
Latinos/as, 35 African Americans, 22 Asian Americans, and 13 as "other." All Peruvian participants self-reported their ethnicity to be of Peruvian origin. Regarding Internet access, $99.1 \%$ of U.S. and $64.7 \%$ of Peruvian students reported having Internet access at home.

Measures

Consistent with the Brislin (1970) technique for translating questionnaires into a new language, a bilingual (English-Spanish), bicultural researcher initially translated all questionnaires into Spanish. Then, an independent bilingual, bicultural researcher translated the Spanish version of the questionnaires back into English. Afterwards, a team of four bilingual, bicultural researchers examined and compared the English-translated version with the original English version in order to address and resolve inconsistencies in translations. As an additional means of insuring appropriate translation of items, before administration of the Spanish version to Peruvian participants, a Peruvian professor of psychology at the institution where this study was conducted reviewed the Spanish version for a final round of modifications. All participants completed the following questionnaires.

\section{Demographics}

Participants indicated their age, gender, ethnicity, religious affiliation, and current residential status (i.e., with whom they lived).

\section{Internet Usage Scale for Sexual Purposes-Modified (Goodson, McCormick, \& Evans, 2000b)}

In order to assess participants' OSA, a modified version of the survey by Goodson et al. was administered to participants. This 25-item modified scale measures participants' use of the Internet for: (1) viewing SEM; (2) seeking out sexual partners; and (3) seeking sex-related information. These three domains were based on the utility subscales used in the study by Goodson et al. with some items being modified to refer to attitudes consistent with the current study. Participants responded to statements using a 4-point Likert-type scale, with response options ranging from 1 (Never) to 4 (Frequently). Scores were averaged, with higher scores reflecting more usage of the Internet for sexual purposes. Based on this sample of participants, the Cronbach reliability alphas were .88 (English) and .84 (Spanish) for the Finding Partners Online subscale, and .88 (English) and .80 (Spanish) for the Information Seeking subscale. Due to a marginally acceptable reliability estimate on the SEM subscale based on data from Peruvian participants (i.e., <.60), one item was discarded, resulting in a 7 -item subscale that was used for analysis purposes for both national groups. This modified subscale obtained Cronbach alphas of .81 (English) and .78 (Spanish), respectively. 


\section{General Internet Usage Scale}

This 6-item scale was developed by the present authors to measure participants' use of the Internet for non-sexual purposes. The development of items was guided by Nie and Erbring (2000), who have identified the most common non-sexual online activities. The items measured participants' use of the Internet for non-sexual entertainment, communication with friends and family, general information seeking, gaming, and seeking out new friends. Participants responded to statements using a 4-point Likert-type scale, with response options ranging from 1 (Never) to 4 (Frequently). Scores were averaged, with higher scores reflecting greater usage of the Internet for general, non-sexually related purposes. Based on the current participants, the Cronbach reliability alphas for this scale were 47 (English) and .57 (Spanish), respectively. These alpha values generally are considered unacceptable against traditional psychometric standards (Tabachnick \& Fidell, 2007). However, such alpha values are not uncommon when items assess distinct behaviors despite forming part of the same scale (Clark \& Watson, 1985; Cortina, 1993). Because our goal was to ascertain the degree to which participants used the Internet for any nonsexually related purposes, we elected to retain the scale and used an overall general Internet usage score for analysis purposes.

\section{Internet Related Problems Scale (IRPS; Widyanto, Griffiths, Brunsden, \& McMurran, 2008)}

This 20-item scale assessed self-reported problems related to using the Internet. Participants responded to statements using a 5-point Likert-type scale, with response options ranging from 1 (Strongly Disagree) to 5 (Strongly Agree). Scores were averaged, with higher scores reflecting the participants' view that Internet usage has caused problematic consequences for them. Based on the current participants, this scale obtained Cronbach reliability alphas of .80 (English) and .82 (Spanish), respectively.

\section{The Brief Symptom Inventory-18 (BSI-18; Derogatis, 2000)}

The BSI-18 is a shortened version of the 53-item BSI (Derogatis, 1993), which was based on the original Symptom Checklist-90Revised (SCL-90-R; Derogatis, 1994). The BSI-18 assesses symptoms of three dimensions of psychological distress: anxiety, depression, and somatization. Participants responded to the 18 items using a 5-point Likert-type scale, with response options ranging from 0 (Not at all) to 4 (Extremely). A total score (the global severity index [GSI]) has been recommended for usage over the subscale scores due to inconsistent findings from factor analyses (see Asner-Self, Schreiber, and Marotta, 2006). Consequently, we used the GSI for data analysis. Score were averaged, with higher scores reflecting more distress. Based on the current participants, this scale obtained Cronbach reliability alphas of .91 (English) and .85 (Spanish), respectively.
UCLA Loneliness Scale-3 (Russell, 1996)

This 20-item scale assessed participants' level of loneliness as defined by a discrepancy between actual and desired social contact. Participants responded to the items using a 4-point Likert-type scale, with response options ranging from 1 (Never) to 4 (Always). Scores were averaged, with higher scores reflecting more loneliness. Based on the current participants, this scale obtained Cronbach reliability alphas of .93 (English) and .86 (Spanish), respectively.

Rosenberg Self-Esteem Scale (RSE; Rosenberg, 1979)

Participants' self-esteem was assessed with this 10-item scale on which they indicated their level of agreement with the statements using a 4-point Likert-type scale, with response options ranging from 1 (Strongly Disagree) to 4 (Strongly Agree). Scores were averaged, with higher scores reflecting higher self-esteem. Based on the current participants, this scale obtained Cronbach reliability alphas of .87 (English) and .73 (Spanish), respectively.

Openness of Sexual Communication Scale (OSCA; Lehr, Dilorio, Dudely, \& Lipana, 2000)

This 8-item scale (4 items in reference to each parent, respectively) measured perceived openness of communication about sex and sex-related topics with parents. All items were responded to using a 5-point Likert-type scale, with response options ranging from 1 (Strongly Disagree) to 5 (Strongly Agree). For this study, we used a total score for analysis purposes based on all 8 items. Scores were averaged, with higher scores reflecting more open parental communication about sex. Based on the current participants, this scale obtained Cronbach reliability alphas of .88 (English) and .82 (Spanish), respectively.

\section{The Multidimensional Scale of Perceived Social Support (MSPSS; Zimet, Dahlem, Zimet, \& Farley, 1988)}

This 12-item scale measured participants' perception of support from family, friends, and significant others. All items were scored on 7-point Likert-type scale, with response options ranging from 1 (Very Strongly Disagree) to 7 (Very Strongly Agree). For this study, we used a total score for analysis purposes based on all 12 items. Scores were averaged, with higher scores reflecting more perceived support. Based on the current participants, this scale obtained Cronbach reliability alphas of .93 (English) and .96 (Spanish), respectively.

Family Environment Scale (FES; Moos, 1974; Moos \& Moos, 1994)

The FES is a 90-item, True-False self-report measure intended to assess the actual, preferred or expected social environment of 
families. The FES contains 10 subscales assessing three sets of underlying domains or dimensions related to the participant's family social climate. For the present study, two subscales, Cohesion and Conflict, from the Relationship dimension, were administered to participants. The 9-item Cohesion subscale assessed the degree of commitment and help family members provide to each other. The 9-item Conflict subscale assessed the degree of conflict within the family. For each subscale, scores were summed, with higher scores reflecting more perceived family cohesion and conflict, respectively. For this study, items were written in reference to participants' families of origin, thereby requiring participants to rate their family environment retrospectively. Negy and Snyder (2006) have garnered evidence for the psychometric appropriateness of the FES when used in this manner. Based on the current sample of participants, tetrachoric $r$ reliability estimates were .88 (English) and .84 (Spanish) for Cohesion, and .89 (English) and .85 (Spanish) for Conflict, respectively.

\section{Religiosity (Batson, Schoenrade, \& Ventis, 1993)}

To measure religiosity, participants responded to the nine items forming the Intrinsic subscale of the Religiosity scale created by Batson (1976; Batson et al., 1993). The original scale measured three constructs related to believing in and practicing a religion. They were labeled Intrinsic (believing in a religion in order to obtain meaning and purpose in life), Extrinsic (using religion for self-serving goals, such as social purposes or a diversion), and Quest (viewing religion as an ongoing process of questioning the tenets of life). We administered only items forming the Intrinsic scale because, as suggested by Batson, they measure individuals' commitment and internal reasons for believing in a religion. Items were responded to using a 5-point Likert-type scale, with response options ranging from 1 (Strongly Disagree) to 5 (Strongly Agree). Scores were averaged, with higher scores reflecting more commitment to a religion. Based on the current participants, this scale obtained Cronbach reliability alphas of .92 (English) and .74 (Spanish), respectively.

Sexual Opinion Survey (SOS; Fisher, White, Byrne, \& Kelley, 1988)

To measure openness to sex and sexuality, participants completed the SOS. This is a 21-item questionnaire on which participants indicated their agreement with statements using a 7-point Likert-type scale, with response options ranging from 1 (Strongly Disagree) to 7 (Strongly Agree). Items were averaged, with higher scores reflecting erotophobia-a relative absence of comfort or interest in sexually related topics and activities, and lower scores reflecting erotophilia-the tendency to be comfortable with and have an interest in sexually related topics and activities. Based on the current participants, this scale obtained Cronbach reliability alphas of .90 (English) and .72 (Spanish), respectively.
Marlowe-Crowne Social Desirability Scale-Short Form (M-C SDS-SF; Reynolds, 1982)

Participants' need to be perceived in a positive light was measured by the 13-item M-C SDS-SF. This scale is a True-False abbreviated version of the M-C SDS. Items were summed, with higher scores reflecting a greater tendency to respond to items in a socially desirable manner. Based on the current participants, the tetrachoric $r$ reliability estimates were .81 (English) and .76 (Spanish), respectively.

\section{Procedure}

Prior to the administration of the questionnaires, one of the researchers provided a brief explanation to students in each participating class about the general nature of the study (i.e., that the study was about on-line sexual behavior). All students who were present in the classes agreed to participate voluntarily. The questionnaire packets were then distributed to students who were in psychology classes at the two respective institutions. The attending researcher remained present until all questionnaires were completed and collected in order to answer any questions students may have had about the study or questionnaires. Approximately $45 \mathrm{~min}$ were required to complete the questionnaires. Students received extra credit in their respective courses for participation.

\section{Results}

Hypothesis 1: Comparing National Groups on Online Sexual Activities

Prior to comparing national groups on OSA, a multivariate analysis of variance (MANOVA) was performed on the data to determine if U.S. and Peruvian young adults differed on any of the additional study variables. The independent variable was nationality (U.S. vs. Peruvian). The dependent variables were age, religiosity, family environment (family cohesion and conflict), perceived social support, erotophobia/erotophilia, perception of their childhood family's openness to discussing sexual matters, and social desirability. Means and SDs of these study variables for both U.S. and Peruvian students are shown in Table 1.

Overall, nationality was associated with a significant multivariate effect, $F(8,434)=70.28, p<.001$, partial $\eta^{2}=.56$. On average, U.S. students were younger than Peruvians, $F(1,441)=$ $175.10, p<.001$, partial $\eta^{2}=.28$, and were more religious, $F(1$, $441)=23.18, p<.001$, partial $\eta^{2}=.05$. U.S. students reported both significantly more cohesion and conflict in their childhood families, as well as more perceived social support from multiple sources, compared to Peruvians, $F_{\mathrm{S}}(1,441)=77.16,73.53$, and 59.68, $p \mathrm{~s}<.001$, partial $\eta^{2}=.15, .14$, and .12 , respectively. U.S. students reported perceiving their childhood families as being 
Table 1 Means and SDs for study variables

\begin{tabular}{|c|c|c|c|c|c|c|c|c|c|c|c|c|c|c|c|c|}
\hline & \multicolumn{2}{|c|}{ Age (in yrs) } & \multicolumn{2}{|c|}{ Religiosity $^{\mathrm{a}}$} & \multicolumn{2}{|c|}{$\begin{array}{l}\text { Family } \\
\text { cohesion }^{\mathrm{b}}\end{array}$} & \multicolumn{2}{|c|}{$\begin{array}{l}\text { Family } \\
\text { conflict }^{\mathrm{b}}\end{array}$} & \multicolumn{2}{|c|}{$\begin{array}{l}\text { Perceived } \\
\text { social support }^{\mathrm{c}}\end{array}$} & \multicolumn{2}{|c|}{ Erotophobia $^{c}$} & \multicolumn{2}{|c|}{$\begin{array}{l}\text { Sexual openness } \\
\text { of childhood } \\
\text { family }^{\mathrm{a}}\end{array}$} & \multicolumn{2}{|c|}{$\begin{array}{l}\text { Social } \\
\text { desirability }^{\mathrm{d}}\end{array}$} \\
\hline & $M$ & $S D$ & $M$ & $S D$ & $M$ & $S D$ & $M$ & $S D$ & $M$ & $S D$ & $M$ & $S D$ & $M$ & $S D$ & $M$ & $S D$ \\
\hline U.S. $(n=310)$ & $18.54 * *$ & 1.49 & $3.27 * *$ & .98 & $6.71 * *$ & 2.32 & $3.96 * *$ & 2.61 & $5.65 * *$ & .90 & $3.62 * *$ & 1.01 & $2.71 * *$ & .94 & $1.57 * *$ & .21 \\
\hline Peruvian $(n=133)$ & 21.56 & 2.81 & 2.82 & .67 & 4.77 & 1.54 & 1.83 & 1.84 & 4.90 & .12 & 3.97 & .84 & 3.29 & .97 & 1.48 & .21 \\
\hline Males $(n=222)$ & 19.62 & 2.13 & $2.94 * *$ & .92 & 5.98 & 1.94 & $2.96^{*}$ & 2.40 & $5.21 *$ & 1.12 & $3.62 *$ & .93 & $3.07 * *$ & .98 & 1.54 & .21 \\
\hline Females $(n=221)$ & 19.10 & 2.50 & 3.31 & .91 & 6.27 & 2.61 & 3.68 & 2.73 & 5.62 & .99 & 3.84 & 1.01 & 2.71 & .93 & 1.57 & .22 \\
\hline
\end{tabular}

$* p<.05$. ** $p<.01$

a Absolute range, 1-5

b Absolute range, 1-9

c Absolute range, 1-7

d Absolute range, 0-13

significantly less open to discussing sexual matters than Peruvians, yet were significantly less erotophobic than Peruvians, $F \mathrm{~s}=35.23$ and $11.60, p \mathrm{~s}<.001$, partial $\eta^{2}=.08$ and .03 , respectively. Finally, U.S. students obtained significantly higher social desirability scores than Peruvians, $F(1,441)=26.11, p<.001$, partial $\eta^{2}=.06$.

To test the hypothesis that U.S. college students would engage in OSA significantly more than Peruvians, a multivariate analysis of covariance (MANCOVA) was performed in order to control for the study variables on which the two national groups differed significantly. The independent variables were nationality (U.S. vs. Peruvian) and gender. The dependent variables were the three OSA subscales that assessed using the Internet for SEM, for pursuing sexual relationships, and seeking out sexrelated information. All eight study variables were treated as covariates. Table 2 shows the means and SDs of the OSA subscales by nationality and gender.

Nationality was associated with a significant multivariate effect, $F(3,429)=49.86, p<.001$, partial $\eta^{2}=.26$. Contrary to prediction, univariate tests indicated that Peruvians reported using the Internet significantly more for viewing SEM than U.S. students, $F(1,431)=25.65, p<.001$, partial $\eta^{2}=.056$. In absolute terms (using the response options as guidelines), the mean scores suggest that Peruvians sometime used the Internet for SEM, whereas U.S. young adults did so rarely. Also contrary to prediction, Peruvians reported using the Internet significantly more for seeking sexual partners than U.S. students, $F(1,431)=$ $8.40, p<.001$, partial $\eta^{2}=.02$. In absolute terms, the mean score for seeking sexual partners hovered around the "rarely" response option for both groups. Finally, and counter to the hypothesis, Peruvians reported using the Internet significantly more for sex-related information seeking than U.S. students, $F(1,431)=$ 137.27, $p<.001$, partial $\eta^{2}=.24$. In absolute terms, the mean score for sex-related information seeking suggests that Peruvians sometimes used the Internet to find sex-related information, whereas U.S. students did so rarely.
Table 2 Means and SDs for OSA

\begin{tabular}{|c|c|c|c|c|c|c|}
\hline & \multicolumn{2}{|c|}{$\mathrm{SEM}^{\mathrm{a}}$} & \multicolumn{2}{|c|}{$\begin{array}{l}\text { Partner } \\
\text { seeking }^{\text {a }}\end{array}$} & \multicolumn{2}{|c|}{$\begin{array}{l}\text { Information } \\
\text { seeking }^{\mathrm{a}}\end{array}$} \\
\hline & $M$ & $S D$ & $M$ & $S D$ & $M$ & $S D$ \\
\hline U.S. males $(n=125)$ & 2.64 & .69 & 1.95 & .77 & 1.57 & .47 \\
\hline U.S. females $(n=189)$ & 1.82 & .80 & 1.58 & .58 & 1.60 & .50 \\
\hline U.S. total $(n=314)$ & 2.15 & $.86^{* *}$ & 1.73 & $.69 * *$ & 1.59 & $.49 * *$ \\
\hline Peruvian males $(n=98)$ & 2.82 & .86 & 2.00 & .74 & 2.43 & .72 \\
\hline Peruvian females $(n=189)$ & 2.83 & $.62 * *$ & 2.48 & $.65 * *$ & 2.50 & .61 \\
\hline Peruvian total $(n=134)$ & 2.83 & .80 & 2.13 & .74 & 2.45 & .69 \\
\hline Males total $(n=222)$ & 2.72 & $.71 * *$ & 1.97 & .76 & 1.95 & .73 \\
\hline Females total $(n=219)$ & 1.98 & .86 & 1.73 & .68 & 1.74 & .62 \\
\hline
\end{tabular}

$* * p<.001$

a Absolute range, 1-4

\section{Moderation Analysis: Nationality}

The moderating role of the study variables on which the two national groups differed was examined further. Hierarchical regression was used to examine the presence of moderators (Frazier, Tix, $\&$ Barron, 2004). Categorical variables were dummy coded and continuous variables were centered. In Block 1, nationality and the proposed moderators (i.e., religiosity, family conflict, family cohesion, perceived social support, sexual openness of childhood family, and erotophilia/erotophobia) were entered. In Block 2 , the interactions of nationality and the potential moderators (e.g., nationality X family cohesion) were entered. A moderator effect was noted with a significant interaction term and an increase in $R^{2}$ (Baron \& Kenny, 1986).

With regard to viewing SEM (see Table 3), Block 1 in the hierarchical regression equation was significant, $F(7,543)=$ $23.94, p<.001$, with nationality $(p<.001)$, religiosity $(p<.001)$, family cohesion $(p<.05)$, and erotophobia $(p<.001)$ being significant predictors. In Block 2, the hierarchical regression 
remained significant, $F(13,537)=25.36, p<.001$, with family cohesion $(p<.05)$, openness of sexual discussions while growing up $(p<.05)$, religiosity $(p<.05)$, erotophobia $(p<.05)$ and the interaction between nationality and religiosity $(p<.05)$, the interaction between nationality and perceived social support $(p<.05)$, and the interaction between nationality and erotophobia $(p<.001)$ being significant predictors. There was a significant increase in $R^{2}\left(R^{2}\right.$ change $\left.=.14, F=20.88, p<.01\right)$.

Median splits were performed to investigate each interaction. With erotophobia, an analysis of variance (ANOVA) revealed that there were significant differences between the groups, $F(3$, $559)=79.08, p<.001$, partial $\eta^{2}=.30$. Scheffe post hoc comparisons indicated that U.S. students with lower erotophobia were significantly more likely to use the Internet to view SEM $(M=2.56, S D=.75)$ than U.S. students with higher erotophobia $(M=1.56, S D=.65)$. With regard to perceived social support, an ANOVA revealed that there were significant differences between the groups, $F(3,553)=31.96, p<.001$, partial $\eta^{2}=$ .15. Scheffe post hoc comparisons indicated that U.S. students with lower perceived social support were significantly more likely to use the Internet to view $\operatorname{SEM}(M=2.37, S D=.84)$ than U.S. students with higher perceived social support $(M=2.01$,

Table 3 Moderated regression analyses for nationality and SEM

\begin{tabular}{|c|c|c|c|}
\hline Regression/variables & $\mathrm{B}$ & $\beta$ & $t$ \\
\hline \multicolumn{4}{|l|}{ SEM } \\
\hline \multicolumn{4}{|l|}{ Step 1: $F(7,543)=23.94, p<.001, r^{2}=.24$} \\
\hline Nationality & -.60 & -.32 & $-7.2 * *$ \\
\hline Family cohesion & .03 & .09 & $2.18 *$ \\
\hline Family conflict & -.01 & -.02 & -.47 \\
\hline Sexual openness of family & .04 & .04 & 1.05 \\
\hline Religiosity & -.21 & -.20 & $-5.03 * *$ \\
\hline Perceived social support & -.05 & -.06 & -1.50 \\
\hline Erotophobia & -.21 & -.21 & $-5.39 * *$ \\
\hline \multicolumn{4}{|c|}{ Step 2: $F(13,537)=25.36, p<.001, r^{2}=.38$} \\
\hline Nationality & -.29 & -.15 & -1.32 \\
\hline Family cohesion & .07 & .20 & $3.01 *$ \\
\hline Family conflict & -.03 & -.06 & -1.43 \\
\hline Sexual openness of family & .13 & .14 & $2.47 *$ \\
\hline Religiosity & -.18 & -.17 & $-2.32 *$ \\
\hline Perceived social support & .01 & .01 & .20 \\
\hline Erotophobia & .19 & .19 & $3.01 *$ \\
\hline Nationality $\times$ family cohesion & -.05 & -.19 & -1.51 \\
\hline Nationality $\times$ family conflict & .03 & .05 & .95 \\
\hline Nationality $\times$ sexual openness & -.12 & -.09 & -1.64 \\
\hline Nationality $\times$ religiosity & .22 & .18 & $2.43^{*}$ \\
\hline Nationality $\times$ perceived social support & -.19 & -.14 & $-2.87 *$ \\
\hline Nationality $\times$ erotophobia & -.74 & -.61 & $-9.49 * *$ \\
\hline
\end{tabular}

$* p<.05 . * * p<.001$
$S D=.85)$. With religiosity, an ANOVA revealed that there were significant differences between the groups, $F(3,547)=38.82$, $p<.001$, partial $\eta^{2}=.18$. Scheffe post hoc comparisons indicated that U.S. students with lower religiosity were significantly more likely to use the Internet to view SEM $(M=2.38, S D=$ .87) than U.S. students with higher religiosity $(M=1.97, S D=$ .83). Further, Peruvians with lower religiosity were also significantly more likely to use the Internet to view SEM $(M=2.97$, $S D=.96)$ than Peruvians with higher religiosity $(M=2.58$, $S D=.67)$.

With regard to seeking out sexual partners, Block 1 in the hierarchical regression equation was significant, $F(7,542)=$ $15.52, p<.001$, with nationality $(p<.001)$, perceived social support $(p<.05)$, erotophilia $(p<.001)$, and sexual openness of the family environment $(p<.05)$ being significant predictors. In Block 2, the hierarchical regression remained significant, $F(13$, $536)=9.35, p<.001$, with nationality $(p<.001)$, family conflict $(p<.05)$, and the interaction between nationality and family cohesion $(p<.05)$ being significant predictors. However, there was not a significant increase in $R^{2}\left(R^{2}\right.$ change $=.02$, $F=1.95)$.

With regard to seeking out sex-related information, Block 1 in the hierarchical regression equation was significant, $F(7,539)=$ $44.12, p<.001$, with nationality $(p<.001)$ and erotophilia $(p<.001)$ being significant predictors. In Block 2 , the hierarchical regression remained significant, $F(13,533)=25.55, p<.001$, with nationality $(p<.001)$, erotophobia $(p<.05)$, the interaction between nationality and family cohesion $(p<.05)$, and the interaction between nationality and perceived social support $(p<.05)$ being significant predictors. However, there was not a significant increase in $R^{2}$ ( $R^{2}$ change $\left.=.02, F=2.83\right)$.

\section{Hypothesis 2: Comparing Genders on Online Sexual} Activities

It also was hypothesized that men-irrespective of nationality-would engage in OSA more than women. The data supported the hypothesis (see Table 2). Gender was associated with a significant multivariate effect, $F(3,441)=9.26, p<.001$, partial $\eta^{2}=.06$. Univariate tests indicated that men reported consuming significantly more SEM on the Internet than women, $F(1,443)=12.69, p<.001$, partial $\eta^{2}=.05$. In absolute terms, the mean scores suggest that men used the Internet for viewing SEM sometimes whereas women rarely used the Internet for that purpose.

There was a significant interaction effect between nationality and gender, $F(3,441)=13.94, p<.001$, partial $\eta^{2}=.09$. Peruvian women reported using the Internet to find sexual partners significantly more than U.S. women, $F(1,443)=13.54, p<.001$, partial $\eta^{2}=.06$. Also, Peruvian women viewed significantly more SEM on the Internet than U.S. women, $F(1,443)=13.35, p<.001$, partial $\eta^{2}=.05$. 
Hypothesis 3: Online Sexual Activities and Maladjustment

It was hypothesized that OSA would minimally, if at all, be linked with maladjustment. In order to test this, a MANOVA was performed on the data to determine if U.S. and Peruvian college students differed on any of the maladjustment variables. The independent variables were nationality (U.S. vs. Peruvian), gender, and usage of the Internet for sexual purposes (Usage vs. No Usage). The dependent variables were Internet-related problems, the BSI-18, the UCLA Loneliness Scale, and the Rosenberg SelfEsteem Scale. Overall, nationality was associated with a significant multivariate effect, $F(4,437)=4.87, p<.001$, partial $\eta^{2}=$ .04. Univariate tests indicated that Peruvians reported modestly, albeit statistically significantly higher levels of distress on the BSI-18 $(M=1.03, S D=.94)$ than U.S. students $(M=.61, S D=$ $.56), F(1,440)=19.09, p<.001$, partial $\eta^{2}=.04$. Gender was associated with a significant multivariate effect, $F(4,437)=$ $4.90, p<.001$, partial $\eta^{2}=.04$. Univariate tests indicate that males reported more symptoms of distress on the BSI-18 $(M=.82$, $S D=.84)$ than females $(M=.64, S D=.57), F(1,440)=7.05$, $p<.01, \operatorname{partial} \eta^{2}=.02$. Most pertinent to the hypothesis, there was no significant main effect of usage of the Internet for sexual purposes, $F(4,437)=1.70$, partial $\eta^{2}=.02$. Moreover, no significant interactions were found.

As a means for clarifying if general Internet usage accounted for any of the observed national differences on the maladjustment variables, a MANCOVA was performed on the data, treating general Internet usage as a covariate (IVs and DVs remained the same). All previously obtained findings remained intact. Specifically, general Internet usage did not account for national or gender differences on maladjustment variables, nor altered the non-significant main effect of usage of the Internet for sexual purposes.

\section{Discussion}

It was hypothesized that U.S. college students would engage in OSA significantly more than Peruvian students. Contrary to the hypothesis, results indicated that Peruvians used the Internet significantly more than U.S. students for viewing SEM, for finding sexual partners, and for seeking sex-related information. This prediction had been based partially on the presumption that Peruvians have less access to the Internet than U.S. college students and, therefore, have less opportunity to use the Internet for OSA. Yet, access to the Internet was not as limited as expected among this sample of Peruvians with most reporting to have Internet access at home. This prediction also was based on previous studies that have noted that the college dorm environment facilitates OSA usage (Young, 2004). Because the concept of living on campus is almost non-existent in Peru, it was expected that U.S. students would use the Internet more for all purposes, yet this was not found. The results suggest that using the Internet for OSA is not necessarily a function of the school environment and may not represent a serious problem among college students as previously proclaimed (Cooper et al., 2001).

The observed differences in usage between U.S. and Peruvian students may be explained by a relatively restrictive sexual environment in Peru along with higher than expected Internet access, which conjointly may lead individuals to use the Internet as a means to express and explore their sexuality. We note that the average amount of time engaged in OSA was negligible across nationality and gender, ranging from roughly one hour per week for U.S. women to five hours per week for Peruvian women (men's average time per week spent on OSA fell in between those two averages, with U.S. men spending roughly $2.5 \mathrm{~h}$ per week and Peruvian men spending roughly $1.5 \mathrm{~h}$ per week). It also bears noting that this cohort of young adults grew up using the Internet and they are at a developmental stage where it is normative to be focused on pursuing sexual and intimate relationships (Erikson, 1959).

Higher levels of erotophilia moderated the relation between nationality and using the Internet for viewing SEM. Specifically, the moderating role of erotophilia was observed only for U.S. students. The ability of erotophilia to moderate the viewing of SEM for Peruvians might have been mitigated by various factors. It is possible that Peru's relatively restrictive sexual society leads many Peruvians, even those with higher levels of erotophobia, to use the Internet for sexual purposes. Further, it is possible that using the Internet for sexual purposes is considered a private matter and possibly even a private social norm. In addition, perceived social support was found to moderate the usage of the Internet for viewing SEM, but, once again, only for U.S. students. This finding suggests that, perhaps for U.S. students, using the Internet to view SEM was related to perceived autonomy from parents more so than for Peruvians. In Peru, for example, it is socially acceptable for children to live at home until they are in their mid-to-late $20 \mathrm{~s}$-even until they marry, irrespective of age-and thus young adults presumably have less autonomy compared to U.S. young adults (Negy, 2008). Further, religiosity was found to moderate the usage of the Internet for viewing SEM for both U.S. and Peruvian students, suggesting that religiosity was an important variable that inhibits the consumption of SEM.

It also was hypothesized that men, irrespective of country, would engage in OSA significantly more than women. This hypothesis was supported generally. As expected, men reported consuming significantly more SEM than women. However, there were no significant differences among men and women's usage of the Internet for finding sexual partners or for seeking sex-related information. The finding with SEM was consistent with previous studies that have shown that men consume more SEM than women (Carroll et al., 2008; Goodson et al., 2001). Among this sample, Peruvian women were significantly more likely to view SEM and to use the Internet to search for partners than U.S. women. It may be that the Peruvian women used the Internet as a means of expressing their sexuality outside the 
public's eye. This finding may also reflect greater notions of equality or liberty among Peruvian women who attend college. Additional data are needed to illuminate this particular finding. Moreover, it bears noting that, in absolute terms, both national groups and genders rarely used the Internet for seeking sexual partners.

Finally, it was hypothesized that OSA would minimally, if at all, be linked with maladjustment. In order to explore this we compared those who reported using the Internet for OSA versus those who did not. No significant differences were found between users and non-users on four indices of maladjustment, even after controlling for general Internet usage. Moreover, given the correlational nature of the data, it may be just as likely that maladjustment leads to OSA (rather than OSA leading to maladjustment).

\section{Limitations}

These results should be considered in light of several limitations. It is difficult to generalize these findings to non-college student populations. Likewise, these results cannot be generalized to all college students in either country given the diversity of universities and their respective student populations. Also, although our two samples of college students were from distinct cultures, it is difficult to know with certainty if cultural differences accounted for any of our observed national differences (Betancourt \& Lopez, 1993). In addition, this study collected sensitive information in a group format and, as a result, participants may not have been completely forthcoming in their responses to questions. It also is possible that participants could discern the true nature of this study and that may have influenced their responses to the questions. Further, given the correlational nature of the data, causal conclusions between OSA and maladjustment cannot be drawn. It also bears noting that we examined U.S. and Peruvian students' usage of OSA, but did not examine their acceptance of those activities. Although college students may engage in OSA, they may not necessarily accept their own behavior in this regard due to feelings of guilt, concerns for morality, and so on. In addition, given that the reliability estimates for the Spanish version of some of the scales (e.g., the SOS) was conspicuously lower than that of the English version, it is possible that some items for the scales may not have been translated adequately or that some of the constructs may have different cultural meanings to the two national groups. Finally, it should be noted that it is difficult to make conclusion about computer and Internet usage due to how quickly technology changes.

\section{Summary and Conclusion}

The cross-national nature of this study provided a unique opportunity to obtain a broader perspective on the pervasiveness of OSA by comparing two relatively similar cohorts of college students but from distinct cultural backgrounds. Counter to prediction, it was found that Peruvians engaged in OSA more than U.S. students, although in absolute terms both national groups engaged in OSA a relatively low number of hours each week.

In addition to gender differences that generally indicated that, irrespective of nationality, men engaged in OSA more than women, four variables appeared to play a role in various degrees with college students' proclivity to engage in OSA. They were erotophobia, religiosity, social support, and parental communication about sex and sexuality. Results clearly indicated that holding relatively more negative attitudes about sex and sexuality (i.e., erotophobia) and being relatively more religious were associated with less OSA. We speculate, though do not know with certainty due to the correlational nature of this study, that erotophobia and religiosity probably act as inhibitors of sexual behavior, including OSA. The role of parental support and open discussions about sex is less clear with respect to OSA. Parent-child discussions that reflect healthy or favorable attitudes about sex and are grounded in medically accurate information may afford young adults the liberty to explore their sexuality, including using the Internet for sexually-related purposes (such as viewing SEM). By contrast, negative, fear-based, and medically inaccurate discussions about sex likely either inhibits emerging adults from exploring their sexuality or may catapult them into sexual exploration and activity while they are ill-equipped to make judicious decisions on matters involving their sexuality and health (Bruckner \& Bearman, 2005; Klein, 2006). The results of this study fell short in illuminating the role of open parent-child discussions about sex and OSA.

Finally, contrary to concerns expressed in the literature and in popular culture that OSA is deleterious to consumers' psychological or emotional well-being, these data-that were examined from diverse angles-paint a less dismal picture of this situation. In addition to the fact that these college students, on average, appear to not engage in OSA extraordinarily frequently, those who did engage in OSA did not seem to differ from those who abstained from OSA on an array of maladjustment markers. Moreover, the link between OSA and maladjustment appeared to be rather mild, suggesting that the concern over OSA is exaggerated and probably unwarranted. We believe that much of the concern over OSA relates primarily to general, morality-based concerns related to sex and sexuality rather than true health concerns.

\section{References}

Ahmad, S., \& Bhugra, D. (2010). Sex and culture. In R. Bhattacharya, S. Cross, \& D. Bhugra (Eds.), Clinical topics in cultural psychiatry (pp. 196-208). London: Royal College of Psychiatrists.

Asner-Self, K. K., Schreiber, J. B., \& Marotta, S. A. (2006). A cross-cultural analysis of the Brief Symptoms Inventory-18. Cultural Diversity and Ethnic Minority Psychology, 12, 367-375.

Bakker, P., \& Taalas, S. (2007). The irresistible rise of porn: The untold story of a global industry. Observatorio (OBS*), 1(1).

Balderston, D., \& Guy, D. J. (1997). Sex and sexuality in Latin America. New York: New York University Press. 
Barak, A., \& Fisher, W. (2002). The future of internet sexuality. In A. Cooper (Ed.), Sex and the Internet: A guidebook for clinicians (pp. 263-280). New York: Brunner-Routledge.

Barak, A., Fisher, W. A., Belfry, S., \& Lashambe, D. (1999). Sex, guys, and cyberspace: Effects of Internet pornography and individual differences on men's attitudes toward women. Journal of Psychology and Human Sexuality, 11, 63-91.

Baron, R. M., \& Kenny, D. A. (1986). The moderator-mediator variable distinction in social psychological research: Conceptual, strategic and statistical considerations. Journal of Personality and Social Psychology, 51, 1173-1182.

Batson, C. D. (1976). Religion as prosocial: Agent or double agent? Journal for the Scientific Study of Religion, 15, 29-45.

Batson, C. D., Schoenrade, P., \& Ventis, W. L. (1993). Religion and the individual: A social-psychological perspective. New York: Oxford University Press.

Betancourt, H., \& Lopez, S. R. (1993). The study of culture, ethnicity, and race in American psychology. American Psychologist, 48, 629-637.

Boies, S. C. (2002). University students' uses of and reactions to online sexual information and entertainment: Links to online and offline sexual behavior. Canadian Journal of Human Sexuality, 11, 77-89.

Boies, S. C., Cooper, A., \& Osborne, C. S. (2004). Variations in internetrelated problems and psychosocial functioning in online sexual activities: Implications for social and sexual development of young adults. CyberPsychology \& Behavior, 7, 207-230.

Brislin, R. W. (1970). Back-translation for cross-cultural research. Journal of Cross-Cultural Psychology, 1, 185-216.

Bruckner, H., \& Bearman, P. S. (2005). After the promise: The STD consequences of adolescent virginity pledges. Journal of Adolescent Health, 36, 271-278.

Caceres, C., Cueto, M., \& Palomino, N. (2008). Policies around sexual and reproductive health and rights in Peru: Conflict, biases and silence. Global Public Health, 3(S2), 39-57.

Carroll, J. S., Padilla-Walker, L. M., Nelson, L. J., Olson, C. D., McNamaraBarry, C., \& Madsen, S. D. (2008). Generation XXX: Pornography acceptance and use among emerging adults. Journal of Adolescent Research, 23, 6-30.

Chou, C., Condron, L., \& Belland, J. C. (2005). A review of the research on Internet addiction. Educational Psychology Review, 17, 363-388.

Clark, L. A., \& Watson, D. (1985). Constructing validity: Basic issues in objective scale development. Psychological Assessment, 7, 309-319.

Cooper, A., Galbreath, N., \& Becker, M. A. (2004). Sex on the internet: Furthering our understanding of men with online sexual problems. Psychology of Addictive Behaviors, 18, 223-230.

Cooper, A., Griffin-Shelley, E., Delmonico, D., \& Mathy, R. (2001). Online sexual problems: Assessment and predictive variables. Sexual Addiction and Compulsivity, 8, 267-285.

Cooper, A., Månsson, S., Daneback, K., Tikkanen, R., \& Ross, M. W. (2003). Predicting the future of internet sex: Online sexual activities in Sweden. Sexual and Relationship Therapy, 18, 277-291.

Cooper, A., Morahan-Martin, J., Mathy, R. M., \& Maheu, M. (2002). Toward an increased understanding of user demographics in online sexual activities. Journal of Sex and Marital Therapy, 28, 105-129.

Cooper, A., Putnam, D. E., Planchon, L. A., \& Boies, S. C. (1999). Online sexual compulsivity: Getting tangled in the net. Sexual Addiction \& Compulsivity, 6, 79-104.

Cortina, J. M. (1993). What is coefficient alpha? An examination of theory and applications. Journal of Applied Psychology, 78, 98-104.

Derogatis, L. R. (1993). Brief Symptom Inventory: Administration, scoring, and procedures manual. Minneapolis, MN: National Computer Systems.

Derogatis, L. R. (1994). SCL-90-R: Administration, scoring and procedures manual (3rd ed.). Minneapolis, MN: National Computer Systems.

Derogatis, L. R. (2000). Brief symptoms inventory (BSI) 18 administration, scoring, and procedures manuel. Minneapolis, MN: National Computer Systems.
Eppright, T., Allwood, M., Stern, B., \& Theiss, T. (1999). Internet addiction: A new type of addiction? Missouri Medicine, 96, 133-136.

Erikson, E. H.(1959). Psychological issues: Identity and the life cycle. New York: International Universities Press.

Escoffery, C., Miner, K. R., Adame, D. D., Butler, S., McCormick, L., \& Mendell, E. (2005). Internet use for health information among college students. Journal of American College Health, 53, 183-188.

Fisher, W. A., White, L. A., Byrne, D., \& Kelley, K. (1988). Erotophobiaerotophilia as a dimension of personality. Journal of Sex Research, 25 , 123-151.

Frazier, P. A., Tix, A. P., \& Barron, K. E. (2004). Testing moderator and mediator effects in counseling psychology research. Journal of Counseling Psychology, 51, 115-134.

Goodson, P., McCormick, D., \& Evans, A. (2000a). Sex on the internet: College students' emotional arousal when viewing sexually explicit materials on-line. Journal of Sex Education and Therapy, 25, 252-260.

Goodson, P., McCormick, D., \& Evans, A. (2000b). Sex and the internet: A survey instrument to assess college students' behavior and attitudes. CyberPsychology and Behavior, 3, 129-149.

Goodson, P., McCormick, D., \& Evans, A. (2001). Searching for sexually explicit materials on the internet: An exploratory study of college students' behavior and attitudes. Archives of Sexual Behavior, 30, $101-118$.

Griffiths, M. (2004). Sex addiction on the internet. Janus Head, 7, 188-217.

Hald, G. M., \& Malamuth, N. M. (2008). Self-perceived effects of pornography consumption. Archives of Sexual Behavior, 37, 614-625.

Hofstede, G. (1998). Comparative studies of sexual behavior: Sex as achievement or as relationship? In G. Hofstede (Ed.), Masculinity and femininity: The taboo dimension of national cultures (pp. 153178). Thousand Oaks, CA: Sage.

Kandell, J. (1998). Internet addiction on campus: The vulnerability of college students. Cyber Psychology and Behavior, 1, 46-59.

Klein, J. D. (2006). America's war on sex: The attack on law, lust, and liberty. Westport, CT: Praeger.

Lehr, S. T., Dilorio, C., Dudley, W. N., \& Lipana, J. A. (2000). The relationship between parent- adolescent communication and safer sex behaviors in college students. Journal of Family Nursing, 6, 180-196.

Lo, V., \& Wei, R. (2005). Exposure to internet pornography and Taiwanese adolescents' sexual attitudes and behavior. Journal of Broadcasting \& Electronic Media, 49, 221-237.

Mackay, J. (2001). Global sex: Sexuality and sexual practices around the world. Sexual and Relationship Therapy, 16, 71-82.

McFarlane, M., Bull, S. S., \& Rietmeijer, C. A. (2002). Young adults on the internet: Risk behaviors for sexually transmitted diseases and HIV. Journal of Adolescent Health, 31, 11-16.

Meston, C. M., \& Buss, D. M. (2007). Why humans have sex. Archives of Sexual Behavior, 36, 477-507.

Moos, R. H. (1974). The family environment scale. Palo Alto, CA: Consulting Psychologists Press.

Moos, R. H., \& Moos, B. S. (1994). Family environment scale manual (3rd ed.). Palo Alto, CA: Consulting Psychologists Press, Inc.

Morahan-Martin, J., \& Schumacher, P. (2000). Incidence and correlates of pathological internet use among college students. Computers in Human Behavior, 16, 13-29.

Negy, C. (2008). Therapy with dissimilar clients: Issues to consider along the road more traveled. In C. Negy (Ed.), Cross-cultural psychotherapy: Toward a critical understanding of diverse clients (2nd ed., pp. 3-22). Reno, NV: Bent Tree Press.

Negy, C., \& Snyder, D. K. (2006). Assessing family-of-origin functioning in Mexican American adults: Retrospective application of the Family Environment Scale. Assessment, 13, 396-405.

Nie, N. H., \& Erbring, L. (2000). Internet and society: A preliminary report. Palo Alto, CA: Stanford Institute for the Quantitative Study of Society Press.

Oddone-Paolucci, E., Genuis, M., \& Violato, C. (2000). A meta-analysis of the published research on the effects of pornography. In C. Violato, E. 
Oddone-Paolucci, \& M. Genuis (Eds.), The changing family and child development (pp. 48-59). Aldershot, UK: Ashgate.

Reynolds, W. M. (1982). Development of reliable and valid short form of the Marlowe-Crowne Social Desirability Scale. Journal of Clinical Psychology, 38, 119-125.

Rosenberg, M. (1979). Conceiving the self. New York: Basic Books.

Russell, D. W. (1996). UCLA Loneliness Scale (version 3): Reliability, validity, and factor structure. Journal of Personality Assessment, 66, $20-40$.

Schwartz, M., Galperin, L., \& Masters, W. (1995). Dissociation and treatment of compulsive reenactment of trauma: Sexual compulsivity. In M. Hunter (Ed.), Adult survivors of sexual abuse: Treatment innovations (pp. 42-55). Thousand Oaks, CA: Sage.

Shaffer, H. J., Hall, M. N., \& Vander Bilt, J. (2000). “Computer addiction”: A critical consideration. American Journal of Orthopsychiatry, 70, 162-168.

Sprecher, S., Harris, G., \& Meyers, A. (2008). Perceptions of sources of sex education and targets of sex communication: Sociodemographic and cohort effects. Journal of Sex Research, 45, 17-26.

Suggs, D., \& Miracle, A. (Eds.). (1993). Culture and human sexuality: A reader. Belmont, CA: Thomson Brooks/Cole Publishing Co.
Tabachnick, B. G., \& Fidell, L. S. (2007). Using multivariate statistics (5th ed.). Boston: Allyn \& Bacon.

Tannahill, R. (1992). Sex in history. London: Scarborough House.

Widyanto, L., Griffiths, M., Brunsden, V., \& McMurran, M. (2008). The psychometric properties of the Internet Related Problem Scale: A pilot study. International Journal of Mental Health and Addiction, 6 , 205-213.

Young, K. S. (1999). Internet addiction: Symptoms, evaluation and treatment. Innovations in Clinical Practice: A Sourcebook, 17, 19-31.

Young, K. S. (2004). Internet addiction: A new clinical phenomenon and its consequences. American Behavioral Scientist, 48, 402.

Zillmann, D., \& Bryant, J. (1988). Pornography's impact on sexual satisfaction. Journal of Applied Social Psychology, 18, 438-453.

Zillmann,D., \& Weaver, J. B. (1999). Effects of prolonged exposure to gratuitous media violence on provoked and unprovoked hostile behavior. Journal of Applied Social Psychology, 29, 145-165.

Zimet, G. D., Dahlem, N. W., Zimet, S. G., \& Farley, G. K. (1988). The multidimensional scale of perceived social support. Journal of Personality Assessment, 52, 30-41. 